\title{
Self-care intervention guidelines on improving knowledge on self-care
}

\author{
Balasaraswathi Seetharaman ${ }^{1 *}$, Premila Lee ${ }^{2}$, Anand Zachariah ${ }^{3}$ and Reka R Kirubakaran ${ }^{4}$ \\ ${ }^{1}$ College of Nursing, Christian Medical College, Kagithapattari, Tamil Nadu, India \\ ${ }^{2}$ College of Nursing, Christian Medical College, Tamil Nadu, India \\ ${ }^{3}$ Department of Medicine, Christian Medical College, Vellore, Tamil Nadu, India \\ ${ }^{4}$ Department of Biostatistics, Christian Medical College, Tamil Nadu, India
}

\begin{abstract}
Background: India has the third largest number of people living with HIV/AIDS and the majority of them (88.55\%) are in the age group of $15-49$ years. The nature of chronicity poses greater demands on PLHIV for comprehensive self- care in order to adopt positive living. The aim of this study was to develop and assess the effectiveness of Self- Care Intervention Guidelines (SCIG) on improving the knowledge on self-care and their Quality of Life (QOL).

Methods: Systematic random sampling technique was used to select the subjects. Adult PLHIV in any clinical stage, on Antiretroviral Therapy (ART) and above 18 years were included in the study. An experimental research design was adopted with a questionnaire to assess the knowledge on self- care and WHO Quality of Life- BREF scale to measure QOL. A total of 150 PLHIV were recruited with 75 in the control group and 75 in the experimental group using the permuted block randomization. Data collection was done at three time points at the ART clinic.

Results: The mean age of subjects in both the groups was almost similar (control-40.86 \pm 8.74 , experimental-39.34 \pm 7.38 ) which reflects that PLHIV are in their productive age group. The mean score difference in knowledge on self- care and QOL between experimental and control group subjects was found to be statistically significant at $\mathrm{p}<0.001$
\end{abstract}

Conclusion: Based on the findings, the study concluded that the SCIG is an essential and effective intervention in improving the knowledge on self-care and QOL of PLHIV.

\section{Introduction}

India has the third largest number of people living with Human Immunodeficiency Virus (HIV) /Acquired Immunodeficiency Syndrome (AIDS) [1]. The impact of HIV on physiological, psychological, social and economic domains of Persons Living with Human Immunodeficiency Virus (PLHIV) is very intense due to the nature of the disease and its complications which are compounded by the side effects of Antiretroviral Therapy (ART). Despite the advancement in the management of HIV/AIDS, PLHIV need to follow self-care activities meticulously so as to enhance health, prevent Opportunistic Infections (OI), manage symptoms and restore health. For effective and adequate self- care, the PLHIV need to be knowledgeable about all the aspects of self-care i.e. compliance with ART, diet, personal hygiene, exercise, management of minor discomforts caused by side effects of ART or HIV itself.

Quality Of Life (QOL) of PLHIV is affected by the symptoms caused by Opportunistic Infections (OIs) and the side effects of ART such as lipodystrophy [2]. Educating PLHIV on common side effects of ART, minor ailments or symptoms due to HIV and OIs and on home care should make positive impact on QOL.

Effectiveness of a structured teaching on symptom management in improving the QOL of PLHIV is reported in the study done in Taiwan [3]. However, similar studies are not reported in India. In view of the aforesaid concerns, the present study was planned "to develop selfcare intervention guidelines and assess its effectiveness in improving the knowledge of PLHIV on self-care and their QOL" The objectives of the study were to evaluate the effectiveness of self- care intervention guidelines on knowledge on self-care and QOL of PLHIV and to identify the relationships of pre-test scores of knowledge on self-care and QOL of PLHIV with their selected socio-demographic variables.

\section{Material and methods}

\section{Design and sampling}

A randomized control design was used. The study was conducted at the ART clinic of a tertiary hospital in Tamil Nadu. A total of 150 subjects were randomly allocated to the experimental and control group by permuted block randomization with 75 subjects in each group. Sample size was determined based on the pilot study findings assuming the SD of 10 points with the power of $80 \%$ and at $5 \%$ level of significance. The calculation was based on the assumption that the measurements on quality of life scale are normally distributed. The

${ }^{*}$ Correspondence to: Balasaraswathi Seetharaman, College of Nursing, Christian Medical College, Kagithapattari, Vellore-632004, Tamil Nadu, India, Tel: 04162282635; Fax: 2223362; E-mail: balasraman@cmcvellore.ac.in

Key words: knowledge on self-care, quality of life, persons living with human immune deficiency virus, self-care intervention guidelines

Received: October 29, 2019; Accepted: November 11, 2019; Published: November 14, 2019 
calculated number was 63 which was increased to 74 per group (a total of 148) to allow for a predicted drop out of $15 \%$ in the follow up.

\section{Sample selection criteria}

Systematic random sampling was used to select the subjects for both the groups. PLHIV in any clinical stage above 18years old were included and those with dementia and chronic co-existing debilitating diseases such as COPD, cancer, renal disease was excluded from the study.

\section{Description of the instrument}

A proforma was used to collect the socio-demographic and clinical data. It included age, sex, marital status, education, family income, type of family, locality, duration of HIV infection, clinical stage of illness, HIV status of spouse, and duration of ART.

The knowledge questionnaire was developed and validated by the experts and the Content Validity Index (CVI) was 0.96 . The reliability of the knowledge questionnaire was established by test-retest method and the calculated ' $r$ ' value was 0.83

The knowledge questionnaire had 25 items comprising different aspects of self- care such as ART, nutrition, physical activity, complementary therapy, prevention, early identification and management of opportunistic infections and management of minor ailments or discomforts. The maximum possible score was 25 . The subjects were categorized into "Adequate Knowledge" $\left(>75^{\text {th }}\right.$ percentile), “Moderately Adequate Knowledge" ( $50^{\text {th }}-75^{\text {th }}$ percentile), and "Inadequate Knowledge" $\left(<50^{\text {th }}\right.$ percentile) based on the percentile scores.

Quality of life of PLHIV was measured by World Health Organization Quality of Life- BREF (WHO QOL- BREF) scale which is a standardized scale comprising of 26 items [4,5]. The maximum possible score was 120 . The scores were interpreted based on the percentile scores as "Very good" $\left(>75^{\text {th }}\right.$ percentile), "Good" $\left(50^{\text {th }}-75^{\text {th }}\right.$ percentile), "Fair" $\left(25^{\text {th }}-50^{\text {th }}\right.$ percentile $)$ and "Poor" $\left(<25^{\text {th }}\right.$ percentile).

\section{Development of study intervention}

The intervention used in this study was the Self- Care Intervention Guidelines (SCIG). SCIG is a manual containing topics on self-care aspects such as "Impact of HIV on immune system; Prevention of re-infection with different types of HIV; Management including Compliance to ART, Nutrition, Personal Hygiene, Physical Activity/ Exercise, Complementary Therapies, Psychological, spiritual and social aspects of management, Prevention of Opportunistic Infections (OIs), early detection and management of OIs and Home care management of minor discomforts.

The SCIG was developed by the investigator based on the intensive literature review and validated by the clinical experts. The investigator also interviewed 20 PLHIV who attended the ART clinic to get to know their understanding about self-care which served as a basis to develop the SCIG.

\section{Data collection procedure}

The data collection was done for a period of six months from March 2014 to August 2014. A written consent was obtained from each subject after explaining about the purposes and the methodology of the study. Then, the subjects were randomized into either control or experimental group using permuted block randomization. Data collection was done at three time points for each subject in both the control and the experimental groups. The subjects were interviewed separately and privately at ART clinic.

Pre-test data were collected from subjects in both the groups by the investigator as soon as they were recruited which included socio-demographic and clinical data and the data on knowledge on self-care and quality of life of PLHIV. Following the pre-test, the subjects in the experimental group were taught about self-care by the investigator individually with discussion, and demonstration. This took approximately 60-90 minutes. Then, each subject was given a copy of the SCIG and asked to follow the self-care instructions appropriately, whereas the control group subjects received standard care. Standard care is the usual care, the PLHIV receive from the health care personnel at the ART Clinic during their monthly visits such as informal teaching, and counselling.

The first post-test assessment was done for both the groups at 4-6 weeks followed by the second post-test at 12-14 weeks. The subjects in the experimental group received reinforcement of teaching after the first post-test assessment. At the end of data collection, the subjects in the control group were also given teaching and a copy of the SCIG.

\section{Pilot study}

A pilot study was conducted on 40 subjects, 20 in each group to assess the feasibility of the design, setting, and methodology and to test the instrument. The study design was found to be feasible.

\section{Results and discussion}

Two subjects from the experimental group and three from the control group were not available for the post-test assessments. Hence, analysis of the data was done for 73 and 72 subjects in the experimental and the control group respectively using Statistical Analysis System (SAS) version 9.2. Frequency and percentages were used to assess the knowledge on self-care and QOL of PLHIV before and after standard care and SCIG. To evaluate the effectiveness of SCIG on knowledge on self-care and QOL between the control and experimental group, independent $t$ test was used. Chi square test, and logistic regression were used to find out the association of pre-test scores of knowledge on self-care and QOL of PLHIV with their socio-demographic and clinical characteristics. The statistical significance was defined as $p<0.05$.

The mean age of the subjects in both the groups was similar (control-40.86 \pm 8.74 , experimental-39.34 \pm 7.38 ). Majority of the PLHIV (56.94\% in control, $60.27 \%$ in experimental) were males. Majority of the PLHIV (66.67\%) in the control group and $54.79 \%$ in the experimental group has completed high school education. Regarding the duration of ART, the majority (56.94\%) in the control and $57.53 \%$ in the experimental group was on ART for more than three years. Both groups were similar with regard to their socio-demographic characteristics $(p>0.05)$ except the age $(\mathrm{p}=0.044)$.

The findings revealed that (Figure 1), in the control group, $15.28 \%$ of PLHIV had adequate knowledge on self-care in the pre-test which became $22.22 \%$ and $31.94 \%$ in the post-test I and II respectively. Whereas in the experimental group (Figure 2), though only $19.18 \%$ of PLHIV had adequate knowledge on self-care in the pre-test, in both the post-tests, all (100\%) subjects had adequate knowledge.

It was noted that most of the study subjects were aware that they should not miss ART, but did not know the importance of taking ART at the right time. This awareness could be due to the counselling received by the PLHIV at ART clinic before initiating ART and during follow-ups. In relation to nutrition, only $21.38 \%$ of them knew that high 


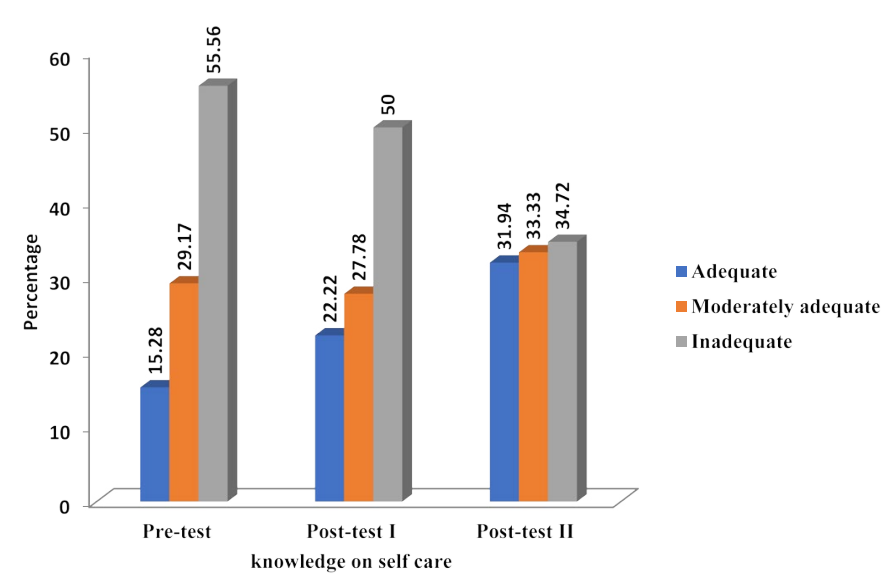

Figure 1. Distribution of PLHIV based on their overall knowledge on self-care during pre-test and two measurements of post-test in control group $(\mathrm{N}=72)$. Figure 1 revealed that, $15.28 \%$ of PLHIV had adequate knowledge and $55.56 \%$ had inadequate knowledge in the pre-test. In the post-test II, almost equal proportion of PLHIV belonged to all three categories of knowledge level (31.94\% - Adequate, 33.33\% - Moderately adequate, $34.72 \%$ - Inadequate).

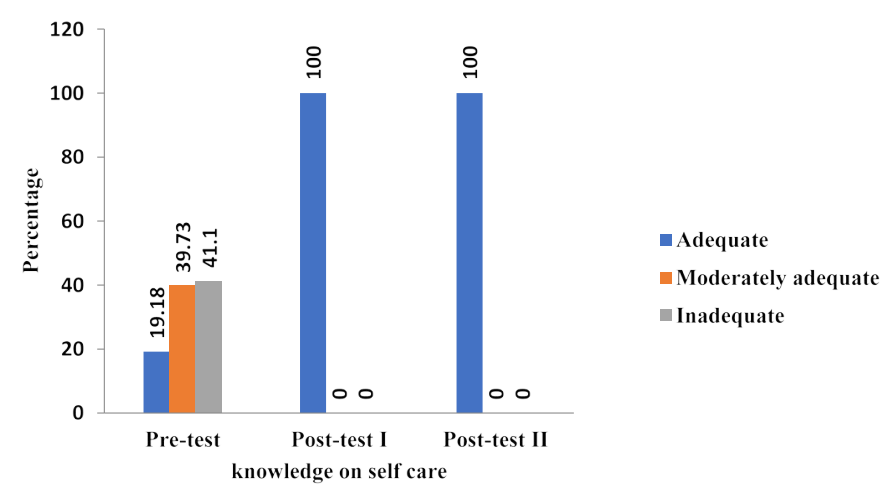

Figure 2. Distribution of PLHIV based on their overall knowledge on self care during pre-test and two mesurements of post-test in experimental group. $(\mathrm{N}=73)$ Figure 2 shows that, $19.18 \%$ of PLHIV in the pre-test had adequate knowledge which became $100 \%$ in both post-test measurements.

protein diet was important for them. Most of them voiced that high fat diet was important for PLHIV. More than half the subjects (69.66\%) did not know the importance of physical exercise and $42.07 \%$ of the PLHIV did not know the benefits of complementary therapy. Most of them $(86.21 \%)$ knew that using condom for sex would prevent reinfection among PLHIV. This could be because of the regular teaching given at ART clinic. This finding is consistent with a study which also reported that $81.10 \%$ of PLHIV knew that unprotected sex with HIV infected person would lead to HIV re-infection [6]. Surprisingly, none of the seroconcordant couples knew the importance of using condom in preventing re-infection with different strains, hence, they did not use condoms for having sex. The couples expressed that "we are already positive". This finding indicates that emphasis should be given to seroconcordant couples on preventing them from re-infection caused by different strains. Tuberculosis is the most common opportunistic infection among PLHIV about which they need to have adequate knowledge in terms of signs and symptoms, early detection and management. In this study, interestingly, the majority $(82.76 \%)$ of them knew about the signs and symptoms of Tuberculosis. The probable reason could be because of the counselling the PLHIV received from the health care personnel at ART clinic before initiation of ART followed by regular ongoing assessment of PLHIV for Tuberculosis.
The pre-test results of QOL in both the groups revealed that around one third (30.56\% in control, $32.88 \%$ in experimental) of the PLHIV had 'poor' scores for their perceived overall QOL.

As shown in figure 3, in the control group, 59.72\% of PLHIV reported very good QOL in the post-test II. On the other hand (Figure 4 ), in the experimental group, all (100\%) subjects were found to have very good QOL.

The mean score difference (Table 1) in knowledge on self- care of PLHIV between the control and experimental group was 0.98 in the pre-test which increased steeply to 8.68 and the difference is statistically significant $(p<0.001)$. The finding of this study is consistent with the study which reported that a structured systematic teaching had shown a significant increase in HIV/AIDS related knowledge, $p<0.01$ [7]. There are other supportive studies which also reported that the education on disease and treatment had shown a significant improvement $(p<0.001)$ regarding knowledge on disease and treatment [8-10].

Similar trends were observed in QOL as well. The mean score difference between the control and the experimental group in the

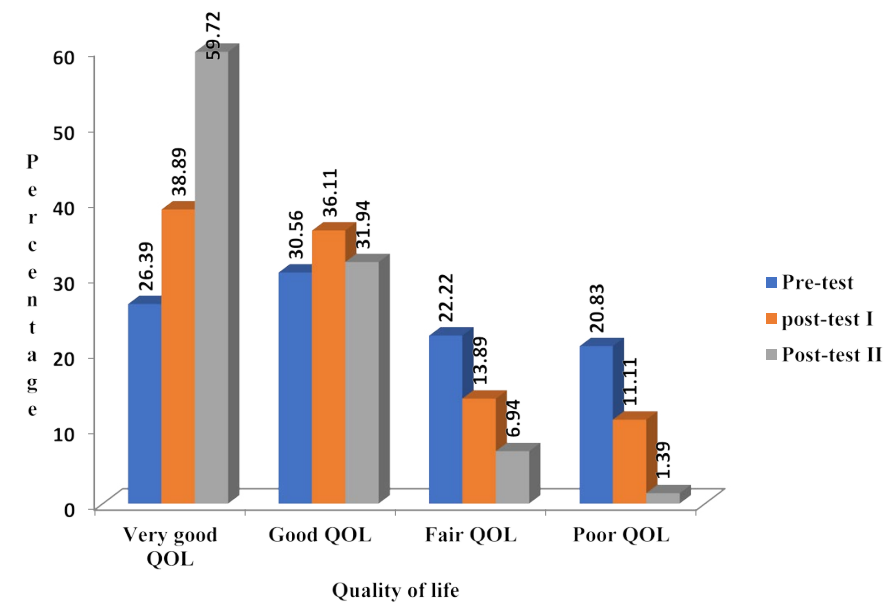

Figure 3. Distribution of PLHIV based on their pre-test and two measurements of post-test on Quality of Life (QOL) in the control group. ( $\mathrm{N}=72$ ). This figure depicts that regarding the QOL, 26.39\% of PLHIV had very good QOL in the pre-test. It is also observed that PLHIV who had poor QOL in the pre-test was $20.83 \%$ which had shown a decrease in the post-test II.

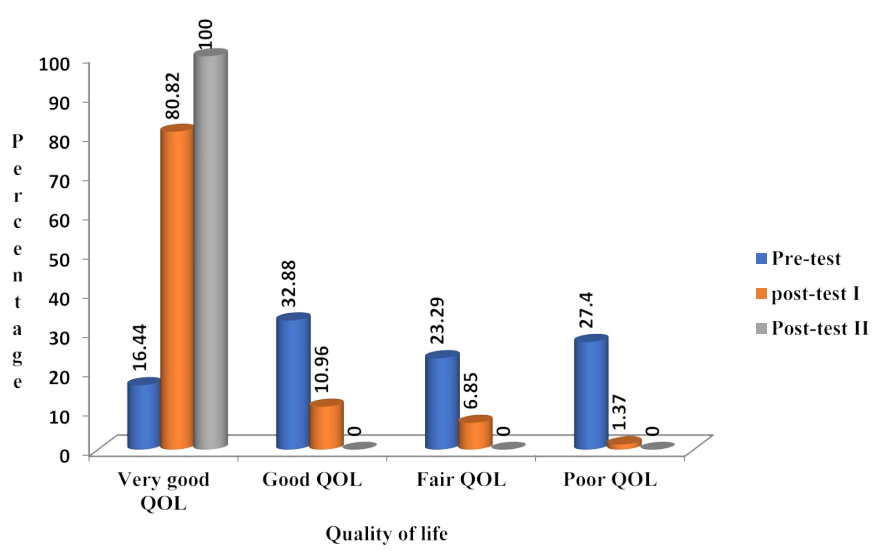

Figure 4. Distribution of PLHIV based on their pre-test and two measurements of post-test on QOL in the experimental group. $(\mathrm{N}=73$ ). With regard to QOL, figure 4 showed $16.44 \%$ of PLHIV had very good QOL in the pre-test which had shown a steep increase in the posttest II. It is also noted that none of them had poor QOL in the post-test II. 
Table 1. Comparison of mean score differences in the pre-test, post-test I and post-test II measurements of PLHIV on knowledge on self- care and quality of life between control and experimental group

\begin{tabular}{|c|c|c|c|c|c|c|c|}
\hline \multirow{2}{*}{ Variables } & \multicolumn{2}{|c|}{ Control $(n=72)$} & \multicolumn{2}{|c|}{ Experimental $(n=73)$} & \multirow{2}{*}{ Mean difference } & \multirow{2}{*}{ t value } & \multirow{2}{*}{ P value } \\
\hline & Mean & SD & Mean & SD & & & \\
\hline $\begin{array}{l}\text { Knowledge on self- care } \\
\text { Pre-test }\end{array}$ & 12.97 & 3.03 & 13.95 & 2.75 & 0.98 & 2.02 & .045 \\
\hline Post-test I & 14.22 & 2.94 & 22.75 & 1.57 & 8.53 & 21.81 & $<.000^{* * * *}$ \\
\hline Post-test II & 15.18 & 2.99 & 23.86 & 0.98 & 8.68 & 23.47 & $<.000^{* * * *}$ \\
\hline $\begin{array}{l}\text { QOL } \\
\text { Pre-test }\end{array}$ & 70.28 & 11.33 & 67.68 & 10.00 & 2.60 & 1.46 & .146 \\
\hline Post-test I & 72.89 & 9.46 & 79.52 & 7.61 & 6.63 & 4.63 & $<.000^{* * * *}$ \\
\hline Post-test II & 76.13 & 7.18 & 86.45 & 5.60 & 10.32 & 9.65 & $<.000^{* * * *}$ \\
\hline
\end{tabular}

With regard to knowledge on self-care of PLHIV the findings showed that (Table 1) the mean score difference between control and experimental group subjects in the post-test I and post-test II is statistically significant at $p<0.001$. Similar trends were observed in QOL of PLHIV also.

pre-test was 2.60 which increased to 10.32 in the post-test II and the difference is significant $(p<0.001)$ which shows definite improvement in the QOL of PLHIV after SCIG. It was also noted that despite the higher pre-test mean scores found among the control group subjects compared to the experimental group, the mean score of experimental group subjects in both the post-test measurements was higher than in the control group and the difference is significant $(p \leq 0.000)$ as shown in table 1 .

The present study findings clearly showed that the SCIG had increased the knowledge on self-care and QOL of PLHIV significantly in the experimental group subjects than in the control group.

Regarding the association of pre-test scores of knowledge on selfcare of PLHIV with their socio demographic variables, it was found that PLHIV with income of Rs.5000- 10000 per month had 0.42 times [95\% CI $(0.21,0.84)]$ more chances of having adequate knowledge when compared the PLHIV with the income below Rs.5000, $(p=0.015)$. Female subjects had 0.83 times, [95\%CI $(0.35,1.98)$ ] more chances of very good QOL as compared to the male subjects. But is not statistically significant $(p=0.080)$. This finding is not consistent with the studies done by Nojomi et al and Chandra et al who reported that the male PLHIV had better quality of life $[11,12]$. Further, the findings of this study showed that widows were found to have 0.05 times [95\%CI $(0.01,0.39)]$ more chances of having a very good QOL compared to the unmarried PLHIV ( $p=0.007)$.

The findings also showed that PLHIV with satisfied sexual relationships with their spouses had better QOL in physical, psychological and social domains compared to PLHIV with unsatisfied relationships $(p<0.01)$. Furthermore, this study showed that the PLHIV who belonged to the skilled occupation group had 2.20 times, $[95 \% \mathrm{CI}(1.02,4.76)]$ more chances to have very good QOLenvironmental domain when compared with the PLHIV who belonged to the unskilled occupation group $(p=0.044)$.

\section{Conclusion}

The findings of this study relied on self-reporting of subjects which is considered to be the limitation. This study has revealed that the selfcare intervention guidelines was effective in improving the knowledge on self-care and quality of life among PLHIV. Therefore, this study recommends one to one education programme for PLHIV attending OPD/ ART clinic followed by reinforcement of teaching during each follow-up visit. This study also recommends that adequate learning materials on self-care in the form of manual should be available to PLHIV in local language. This study is part of the major Ph.D. research work.

\section{Acknowledgement}

Author expresses her gratitude to the institution for all the administrative support including the approval from the institution review board and research committee of College of Nursing. The author wishes to thank all the patients who had taken part in this study and extended co-operation throughout the study period.

\section{Conflicting interest}

None.

\section{References}

1. Park K (2013) Park's Test book of preventive and social medicine. (22nd Edn). $2 \mathrm{M} / \mathrm{s}$ Banarsidas Bhanot Publishers. 278

2. Bing EG, Hays RD, Jacobson LP, Chen B, Gange SJ, et al. (2009) Health related quality of life among people with HIV disease: results from the multicenter AIDS cohort study. Qual Life 9: 55-63. [Crossref]

3. Chiou PY, Kuo BI, Lee MB, Chen YM, Chuang P, et al. (2006) A program of symptom management for improving quality of life and drug adherence in AIDS/HIV patients. $J$ Adv Nurs 55: 169-179. [Crossref]

4. Skevington SM, Lotfy M, O'Connell KA; WHOQOL (2004) Group the World Health Organization's WHOQOL-Bref quality of life assessment: Psychometric properties and results of the international field trial. A Report from the WHOQOL Group. Qual Life Res 13: 299-310. [Crossref]

5. Fang CT, Hsiung PC, Yu CF, Chen MY, Wang JD (2002) Validation of the World Health Organization Quality of Life instrument in patients with HIV infection. Qual Life Res 11: 753-762. [Crossref]

6. Olowookere SA, Fatiregun AA, Akinyemi JO, Bamgboye AE, Osagbemi GK (2008) Prevalence and determinants of non-adherence to highly active antiretroviral therapy among people living with HIV/AIDS in Ibadan, Nigeria. J Infect Dev Ctries 2: 369372. [Crossref]

7. Nielsen-Bohlman L, Panzer AM, Dig DA (2004) Health literacy a prescription to end confusion Institute of Medicine. Washington, DC. The National Academies Press.

8. Mini KV, Adepu R, Mothi SN, Swamy T (2010) Impact of education on knowledge, attitude and practice of HIV/AIDS patients towards their disease Management: a survey. IJOPP 3 .

9. Salam RA, Haroon S, Ahmed HH, Das JK, Bhutta ZA (2014) Impact of communitybased interventions on HIV knowledge, attitudes, and transmission. Infect Dis Poverty 3: 26. [Crossref]

10. Rajesh R, Vidyasagar S, Varma DM, Guddattu V, Hameed A (2013) Evaluating the impact of educational interventions on use of HAART and adherence behaviour in Indian human Immunodeficiency virus positive patients: prospective Randomized Controlled Trial. J AIDS Clin Re 4. 
11. Chandra PS, Satyanarayana VA, Satishchandra P, Satish KS, Kumar M (2009) Do Men and Women with HIV differ in their Quality of life? A Study from South India. AIDSBehav 13: 110-117. [Crossref]
12. Nojomi M, Anbary K, Ranjbar M (2008) Health-related quality of life in patients with HIV/AIDS. Arch Iranian Med 11: 608-612. [Crossref]

Copyright: (C2019 Seetharaman B. This is an open-access article distributed under the terms of the Creative Commons Attribution License, which permits unrestricted use, distribution, and reproduction in any medium, provided the original author and source are credited. 